\title{
The association of pretreatment serum albumin with outcomes in bladder cancer: a meta-analysis
}

This article was published in the following Dove Press journal:

OncoTargets and Therapy

Jialin $\mathrm{Li}^{1, *}$

Yusheng Cheng',*

Guanghua Liu'

Zhigang Ji'

'Department of Urology, Peking Union Medical College Hospital, Chinese Academy of Medical Sciences and Peking Union Medical College, Beijing 100730, China; ${ }^{2}$ Department of Liver Transplantation, Third Affiliated Hospital of Sun Yat-sen University, Guangzhou, China

*These authors contributed equally to this work
Correspondence: Zhigang Ji

Department of Urology, Peking Union Medical College Hospital, Chinese Academy of Medical Sciences and Peking Union Medical College, I\#, Shuaifuyuan, Dongcheng District, Beijing 100730, China

Email jzg1 129@gmail.com
Background: Recently, numerous studies have shown that pretreatment serum albumin can be closely associated with the prognosis of patients with bladder cancer (BC). However, the conclusions regarding this issue are still conflicting. Hence, in this study, we performed a systematic review and meta-analysis to determine the prognostic significance of pretreatment serum albumin in BC patients.

Materials and methods: A systematic search was carried out in PubMed, Embase, and Web of Science. A total of 16 studies involving 13,917 patients were included in the current metaanalysis. hazard ratios (HRs) and 95\% CIs were pooled to assess the intensity of association. Moreover, heterogeneity, sensitivity analysis and publication bias were explored. All statistical analyses were conducted by STATA 12.0 .

Results: Our results suggested that a decreased pretreatment serum albumin level was closely related to a worse overall survival (HR $1.88,95 \%$ CI 1.43, 2.48; $P<0.01$ ) and cancer-specific survival (HR 1.65, 95\% CI 1.08, 2.52; $P=0.02$ ). In addition, from the results of this metaanalysis, it was also observed that a lower pretreatment serum albumin level was linked to higher incidence of postoperative 30-day complication (odds ratio [OR] 1.41, 95\% CI 1.03, $1.91 ; P=0.03$ ) and 90 -day mortality (OR 2.51, 95\% CI 1.82, 3.48; $P<0.01$ ). Furthermore, these findings were demonstrated to be reliable by our sensitivity and subgroup analysis stratified by ethnicity, analysis type, and cutoff value.

Conclusion:Our results revealed that a lower pretreatment serum albumin level yields a poor long-term prognosis and increases the risks of postoperative complication and mortality in $\mathrm{BC}$ patients and can be applied to risk stratification and individualized therapy in $\mathrm{BC}$ patients.

Keywords: albumin, prognosis, mortality, bladder cancer, meta-analysis

\section{Introduction}

Bladder cancer $(\mathrm{BC})$, the most common urinary tract carcinoma, was reported to have an estimated 76,960 new cases and result in 16,390 deaths in the USA in 2016 alone. ${ }^{1}$ BC is characterized with great heterogeneity, but it is still divided into two main subsets in clinical practice: non-muscle-invasive $\mathrm{BC}$ (NMIBC) and muscle-invasive $\mathrm{BC}(\mathrm{MIBC}){ }^{2}$ Although nearly $75 \%$ of $\mathrm{BC}$ patients are diagnosed as having NMIBC that only invades the mucosa or submucosa of bladder, approximately $50 \%-70 \%$ of NMIBC patients experience disease recurrence and about $10 \%-30 \%$ of NMIBC patients advance into $\mathrm{MIBC}$ that is rather aggressive and tends to metastasize. ${ }^{3}$ Worse still, the majority of MIBC is related to high mortality, in spite of the improved therapeutic modalities available currently. ${ }^{4}$ Thus, it is very urgent to develop prediction models to differentiating patients from diverse prognosis, and those with an adverse prognosis may benefit from early comprehensive therapy. Up to now, tumor stage, grade, and metastasis are considered as the main prognostic factors for BC. Nevertheless, the currently used 
system usually fails to precisely predict the prognosis of $\mathrm{BC}$ patients with disparate tumor backgrounds. ${ }^{5}$ In this regard, novel biomarkers that can identify patients with unfavorable outcomes when applied alone, or combined with other clinicopathological characteristics, are needed to accurately guide clinical decisions.

Serum albumin is produced in the liver and occupies a large proportion of serum protein. The physiological serum level of albumin fluctuates from 3.5 to $5.0 \mathrm{~g} / \mathrm{dL}$ in adults. Admittedly, the concentration of serum albumin inferior to $3.5 \mathrm{~g} / \mathrm{dL}$ is defined as hypoalbuminemia. ${ }^{6}$ Serum albumin is tightly correlated with the severity of malnutrition and is often applied to assessing nutritional status. ${ }^{7}$ In addition, numerous studies have suggested that the level of serum albumin is also influenced by inflammatory response. Thus, serum albumin has the potential to be applied as a reliable biomarker of inflammation. ${ }^{8,9}$ Particularly, malnutrition and chronic inflammation response often accelerate the progression of the disease by promoting the development of tumor cachexia, ${ }^{10}$ which hints that serum albumin, as an indicator for the status of malnutrition and chronic inflammation, might be related to the prognosis in patients with cancer. Thus, in recent years, many studies were conducted to investigate the association between serum albumin and prognosis in various cancers, and the majority of studies indicated that the decreased pretreatment serum albumin is closely related to worse prognosis of tumor patients..$^{9,11-14}$ Specifically, some of these studies have focused on exploring the association of pretreatment serum albumin with the prognosis of BC patients. ${ }^{15-31}$ Nevertheless, the prognostic value of pretreatment serum albumin in $\mathrm{BC}$ patients is inconsistent. Some studies showed that decreased pretreatment serum albumin was associated with worse prognosis of BC patients, but others indicated that there was no relationship between pretreatment serum albumin and prognosis of BC patients. Therefore, it is imperative to perform a meta-analysis to assess the prognostic significance of pretreatment serum albumin in BC patients.

\section{Materials and methods Data sources and search}

A systematic search was carried out in PubMed, Embase, and Web of Science (up to November 12, 2017). The search strategy was generated by combining the following terms: "bladder cancer or bladder carcinoma or bladder tumor or cystectomy" and "albumin or hypoalbuminemia" and "prognos* or survival or outcome."

\section{Study selection}

The studies that met the following criteria were included: 1) the diagnosis of $\mathrm{BC}$ patients was histopathologically confirmed; 2) retrospective study or perspective study design; and 3) the relationship between preoperative serum albumin and long-term survival, short-term postoperative outcomes, or postoperative mortality should be analyzed, and full text of studies should be accessible to extract these data. In contrast, studies meeting the following criteria were excluded: 1) abstracts, case reports, reviews, editorials, or letters; 2) overlapping or duplicate data among studies; 3) studies about the BC patients who did not undergo radical surgical treatment; 4) studies focusing on the correlation between preoperative serum albumin and non-BCs. The language and region of publications were not restricted in this meta-analysis.

\section{Data collection and quality evaluation}

Data from eligible studies were extracted by two authors (Jialin Li and Yusheng Cheng) independently, and any divergence was addressed by the second coauthor (Guanghua Liu). Data extracted from eligible publications included the following: first author, publication year, country, case number, age, sex, treatment methods, median follow-up months, the cutoff value for pretreatment serum albumin, and the outcomes of our interest that included overall survival (OS), cancer-specific survival (CSS), postoperative 30-day complication (30dC), and 90-day mortality (90dM). Multivariate end points were preferred than univariate end points if both were reported in studies. If survival data were not provided directly in the eligible studies, described by a Kaplan-Meier curve, the Engauge Digitizer version 4.1 was applied to calculate and extract the hazard ratio (HR) and its $95 \%$ CI. ${ }^{32}$ The Newcastle-Ottawa Scale (NOS) ${ }^{33}$ was used to assess the quality of eligible publications. The scores of NOS ranged from 0 to 9 , and in this meta-analysis, studies with scores of 6 or more were considered as high-quality publications.

\section{Statistical analyses}

The statistical processes of this meta-analysis were fulfilled using Stata version 12.0 (StataCorp LP, College Station, TX, USA). Synthesized HRs and their 95\% CIs were used to assess the association of pretreatment serum albumin with OS and CSS. In addition, pooled odds ratios (ORs) and their 95\% CIs were used to assess the relationship of pretreatment serum albumin with postoperative $30 \mathrm{dC}$ and $90 \mathrm{dM}$. Heterogeneity among studies was assessed by Chi-square-based $Q$ and $I^{2}$ tests. ${ }^{34}$ If $I^{2}>50 \%$ or $P<0.01$, the heterogeneity of the synthesized data was considered statistically significant, and then a random-effects model was used; otherwise, fixed-effects model was conducted. Sensitivity analyses were carried out 
to investigate the factors contributing to the heterogeneity and test the stability of the pooled results in this meta-analysis. Sensitive analysis was conducted by omitting each study.

\section{Results \\ Study selection}

The strategy of search and selection is shown in Figure 1. The initial literature search yielded 185 potentially relevant studies with 41 from PubMed, 81 from Embase, and 63 from Web of Science. Of all identified records, 27 duplicated articles were removed. In the full-text screening for remaining 158 publications, 126 articles were excluded, including reviews $(n=9)$, meeting abstracts $(n=26)$, irrelevant studies $(n=74)$, and no extracted data $(n=33)$. Finally, a total of 16 studies with 13,917 cases were included in this meta-analysis. ${ }^{15-30}$

\section{Characteristics of eligible studies and quality assessment}

Summary characteristics of eligible studies are presented in Table 1. The 16 included articles were published between 2011 and 2017. The region of studies included China $(n=2)$, Japan $(n=2), \operatorname{USA}(n=7)$, Canada $(n=1), \operatorname{UK}(n=1)$, France $(n=1), \operatorname{Egypt}(n=1)$, and Korea $(n=1)$. The cutoff value for pretreatment serum albumin varied from 3.5 to 4 . The sample size of the included studies ranged from 31 to 5,568. The OS was analyzed in seven articles with 3,374 patients. ${ }^{17,19,21-24,29}$ The CSS was investigated in five publications involving 1,086 patients, ${ }^{16,21-23,26} 30 \mathrm{dC}$ was inquired into in seven articles with 11,589 patients, ${ }^{15,17,18,20,23,25,30}$ and $90 \mathrm{dM}$ was explored in six studies with 8,523 patients. ${ }^{15,17,18,23,27,28}$ The cutoff value of pretreatment serum albumin applied in most publications was $3.5 \mathrm{~g} / \mathrm{dL}$ (the lower limit of normal). Based on the NOS, most of the included studies scored ranging from 6 to 7 (Table 2), indicating that the quality of eligible studies was high.

\section{Impact of pretreatment serum albumin on OS and CSS}

A total of seven articles were included in the meta-analysis of OS in BC patients. ${ }^{17,19,21-24,29}$ Because of the significant heterogeneity $\left(I^{2}=60.2 \% ; P<0.01\right)$, random-effects model was used to synthesize the HR for the impact of pretreatment serum albumin on OS. The result showed that patients with decreased pretreatment serum albumin had a significant shorter OS (HR 1.88, 95\% CI 1.43, 2.48; $P<0.01$; Figure 2). Regarding the CSS, five publications provided the available data for pooling analysis, ${ }^{16,21-23,26}$ which indicated that low level of pretreatment serum albumin was also significantly correlated with worse CSS (random-effects model: HR 1.65, 95\% CI 1.08, 2.52; $P=0.02$; heterogeneity: $I^{2}=86.7 \%$; $P<0.01$; Figure 3).

\section{Impact of pretreatment serum albumin on postoperative $30 \mathrm{dC}$ and $90 \mathrm{dM}$}

In the eligible studies, seven inquired into the relationship between preoperative serum albumin and $30 \mathrm{dC}$ in BC patients. ${ }^{15,17,18,20,23,25,30}$ Since the significant heterogeneity exists among the included articles $\left(P<0.01 ; I^{2}=\right.$ $80.9 \%$ ), random effects were carried out to pool the data. After synthesizing the data, we found that a low pretreatment serum albumin was closely related to worse $30 \mathrm{dC}$ (OR 1.41, 95\% CI 1.03, 1.91; $P=0.03$; Figure 4). In addition,

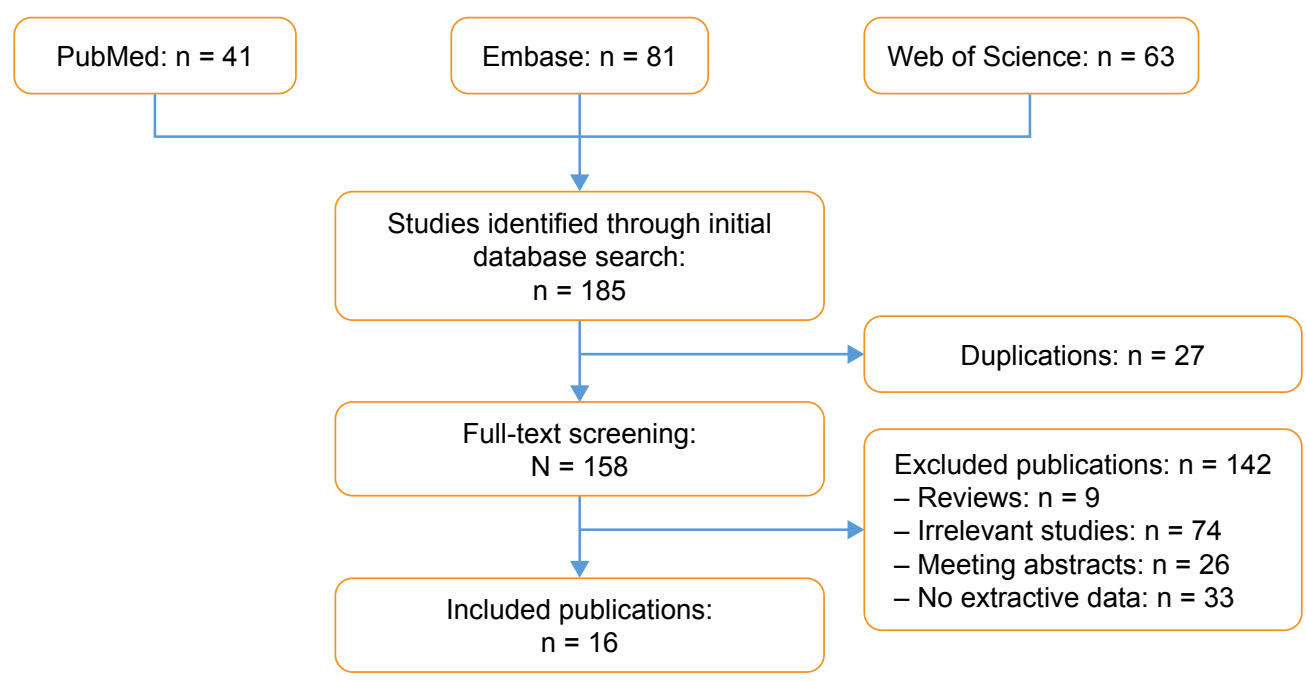

Figure I Flow diagram of study selection. 
Table I The main characteristics of the included studies

\begin{tabular}{|c|c|c|c|c|c|c|c|c|c|}
\hline Study & Country & $\begin{array}{l}\text { Tumor } \\
\text { type }\end{array}$ & $\begin{array}{l}\text { Case number } \\
\text { (LSA/HSA) }\end{array}$ & $\begin{array}{l}\text { Age } \\
\text { (years) }\end{array}$ & $\begin{array}{l}\text { Sex (male/ } \\
\text { female) }\end{array}$ & $\begin{array}{l}\text { Surgical } \\
\text { treatment }\end{array}$ & $\begin{array}{l}\text { Follow-up } \\
\text { (months) }\end{array}$ & $\begin{array}{l}\text { Survival } \\
\text { analysis }\end{array}$ & $\begin{array}{l}\text { Cutoff value } \\
\text { of serum } \\
\text { albumin } \\
(\mathrm{g} / \mathrm{dL})\end{array}$ \\
\hline Caras et $\mathrm{al}^{15}$ & USA & $B C$ & $1,292 / 4,282$ & 65 & $4,228 / 1,340$ & $\mathrm{RC}$ & 1 & NR & 3.5 \\
\hline Chan et al $^{16}$ & China & $\mathrm{BC}$ & $62 / 55$ & $68 \pm 10$ & $99 / 18$ & $\mathrm{RC}$ & 31 & CSS, OCS, OS & 3.9 \\
\hline Djaladat et $\mathrm{al}^{17}$ & USA & $\mathrm{BC}$ & $197 / 1,274$ & 67 & I,I54/3I7 & $\mathrm{RC}$ & 12.4 & OS & 3.5 \\
\hline Garg et $\mathrm{al}^{18}$ & USA & $\mathrm{BC}$ & $150 / 947$ & 68 & $831 / 266$ & $\mathrm{RC}$ & 25.2 & NR & 4 \\
\hline Hinata et $\mathrm{a}^{19}$ & Japan & $B C$ & NR & 68.6 & $575 / 155$ & $\mathrm{RC}$ & 52 & OS & 3.5 \\
\hline Johnson et $\mathrm{al}^{20}$ & USA & $\mathrm{BC}$ & $102 / 587$ & 73 & $530 / 159$ & $\mathrm{RC}$ & 1 & NR & 3.5 \\
\hline Krane et $\mathrm{al}^{21}$ & USA & BC & NR & 67.4 & $55 / 13$ & $\mathrm{RC}$ & 25 & OS, CSS & 3.5 \\
\hline Ku et $\mathrm{al}^{22}$ & Korea & $\mathrm{BC}$ & NR & 65.1 & $362 / 57$ & $\mathrm{RC}$ & 37.7 & OS, CSS & 3.5 \\
\hline Lambert et $\mathrm{al}^{23}$ & UK & $B C$ & $31 / 156$ & 67.4 & $153 / 34$ & $\mathrm{RC}$ & 26.2 & OS, CSS & 3.5 \\
\hline Laurent et $\mathrm{a}^{24}$ & France & $B C$ & $95 / 98$ & 75.2 & $164 / 29$ & $\mathrm{RC}$ & 9.1 & OS & 3.5 \\
\hline Lavallee et $\mathrm{a}^{25}$ & Canada & $\mathrm{BC}$ & $341 / 1,090$ & 70 & I,819/484 & $\mathrm{RC}$ & NR & NR & NR \\
\hline Liu et $\mathrm{a}^{26}$ & China & $\mathrm{BC}$ & $129 / 167$ & 61.71 & $250 / 45$ & $\mathrm{RC}$ & 72 & CSS & 4.0 \\
\hline Morgan et $\mathrm{al}^{27}$ & USA & $\mathrm{BC}$ & $30 / 139$ & 78.8 & $122 / 47$ & $\mathrm{RC}$ & 3 & NR & 3.7 \\
\hline Mursi et $\mathrm{al}^{28}$ & Egypt & $\mathrm{BC}$ & $24 / 7$ & 58.4 & $22 / 9$ & $\mathrm{RC}$ & 3 & NR & 3.5 \\
\hline Nakagawa et $\mathrm{al}^{29}$ & Japan & $\mathrm{BC}$ & NR & 69 & $248 / 58$ & $\mathrm{RC}$ & 6.8 & OS & 3.5 \\
\hline Sharma et $\mathrm{al}^{30}$ & USA & $\mathrm{BC}$ & NR & 70.1 & $209 / 65$ & $\mathrm{RC}$ & NR & NR & 4.0 \\
\hline
\end{tabular}

Abbreviations: LSA, low serum albumin; HSA, high serum albumin; BC, bladder cancer; CSS, cancer-specific survival; OS, overall survival; RC, radical cystectomy; NR, not reported.

six publications involved 90dM. ${ }^{15,17,18,23,27,28}$ The results from meta-analysis of six publications suggested that a decreased preoperative serum albumin was significantly related to worse 90dM (OR 2.51, 95\% CI 1.82, 3.48; $P<0.01$; heterogeneity: $P=0.295, I^{2}=18.2 \%$; Figure 5).

\section{Subgroup analysis and sensitivity analysis}

Taking into account that significant heterogeneity existing among the included studies might challenge the reliability and robustness of the results from this meta-analysis, subgroup analysis and sensitivity analysis were performed to explore the potential source of heterogeneity and meanwhile determine whether the results of this meta-analysis were reliable. Sensitivity analysis was conducted by omitting each study. The results showed that the pooled HRs for OS (Figure 6) and CSS (Figure 7) as well as ORs for 30dC (Figure 8) and 90dM (Figure 9) did not alter significantly, which demonstrated the strength of our findings. In addition, the significance of pretreatment serum albumin was further evaluated via subgroup analysis according to ethnicity, analysis type, and cutoff value, and its results indicated that our findings were reliable (Table 3).

\section{Discussion}

To the best of our knowledge, our meta-analysis is the first comprehensive study to systematically assess the prognostic significance of pretreatment serum albumin in BC patients. From the final results of this meta-analysis, there was a substantial association between decreased pretreatment serum albumin level and unfavorable long-term survival of BC patients with a pooled HR of 1.78 (95\% CI 1.39-2.28) for OS and 1.65 (95\% CI 1.08-2.52) for CSS. In addition, our meta-analysis also demonstrated that decreased pretreatment serum albumin level was closely correlated with higher incidence of postoperative $30 \mathrm{dC}$ and $90 \mathrm{dM}$. Furthermore, in general, our subgroup analysis and sensitivity analysis also validated the robust of the combined HR.

Pretreatment serum albumin is closely correlated with the outcomes of $\mathrm{BC}$ and other malignancies, but the underlying mechanisms for this have not been fully elucidated. However, the association of nutrition and inflammation with serum albumin has been considered as one of the explanations for this. The malnutrition and chronic inflammation often occur in the initiation and progression of malignant tumors, and they can contribute to the worsening of cancer patients and finally lead to cachexia, which will increase the risk of posttreatment complications and mortality and shorten the long-term survival. The loss of appetite and the consumption of body component usually result in malnutrition in cancer patients, and this is mirrored by hypoalbuminemia and pitting edema. The systematically chronic inflammation in malignant tumor patients also affects the serum albumin level. Due to the inflammatory response to cancer, many pro-tumor cytokines, including tumor necrosis factor, interleukin-1, interleukin-6, and interleukin-8, are released, which can directly suppress the function of hepatic cells to generate 


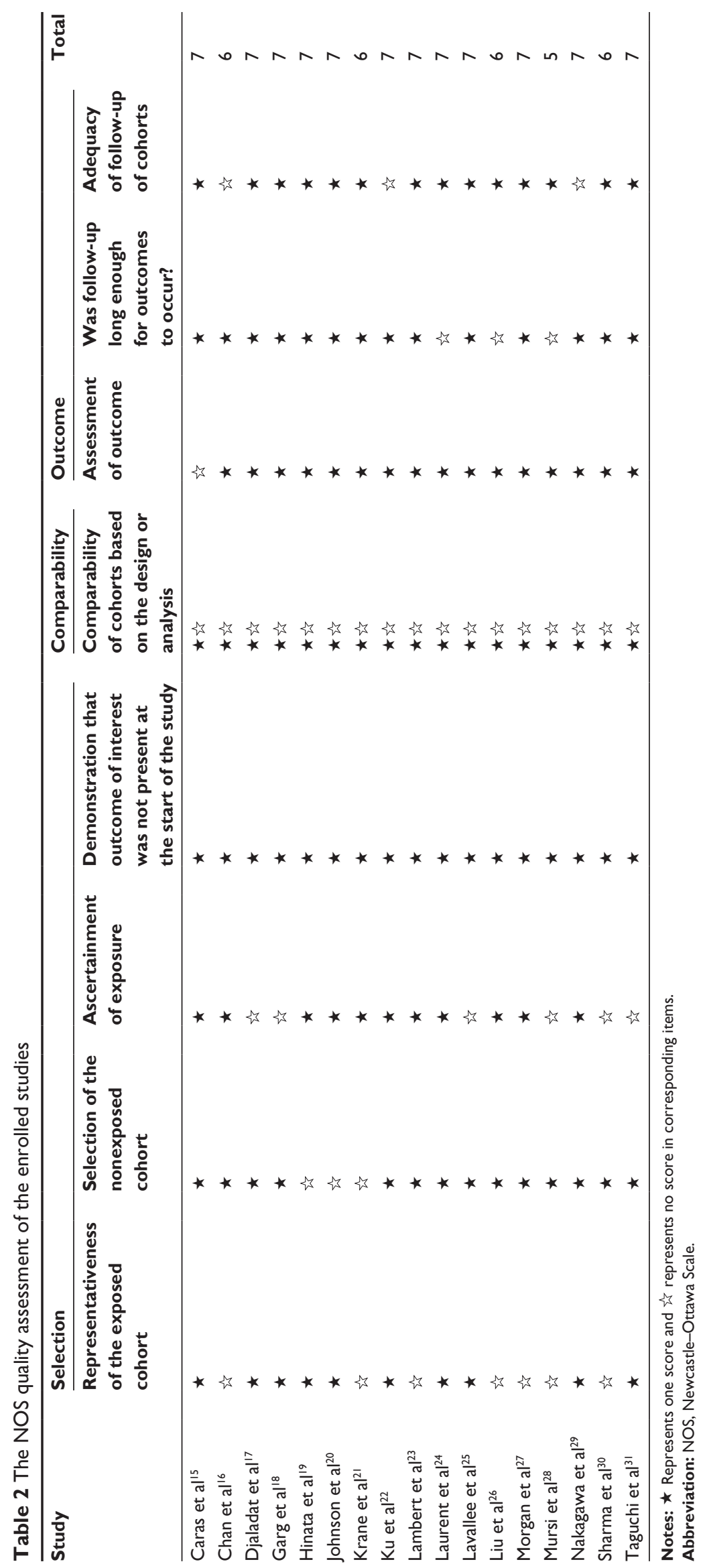




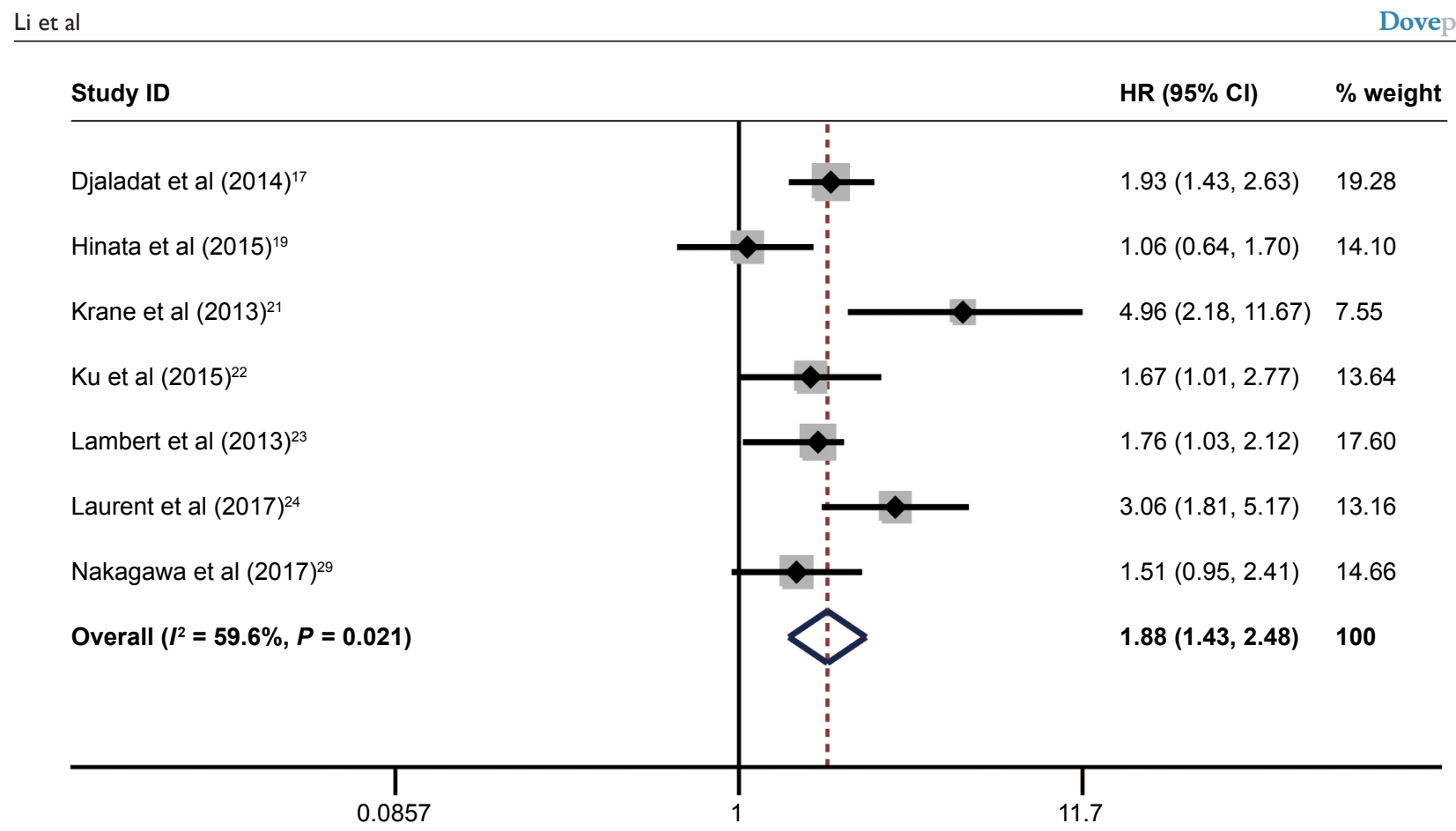

Figure $\mathbf{2}$ The prognostic significance of low pretreatment serum albumin level on OS in BC.

Note: Weights are from random-effects analysis.

Abbreviations: BC, bladder cancer; HR, hazard ratio; OS, overall survival.

albumin. ${ }^{35,36}$ In addition, the tumor necrosis factor produced by tumor cells augments the permeability of capillaries, leading to the direct loss of albumin from the circulatory system. ${ }^{37}$ Furthermore, micro-metastases located in liver during the late stage of cancers are capable of impairing the liver function, which also inhibits the synthesis of albumin. ${ }^{35}$ Hence, the decreased pretreatment serum albumin level is related to the worse prognosis of cancer patients, and consequently it might be an effective and inexpensive prognostic biomarker for cancer patients.

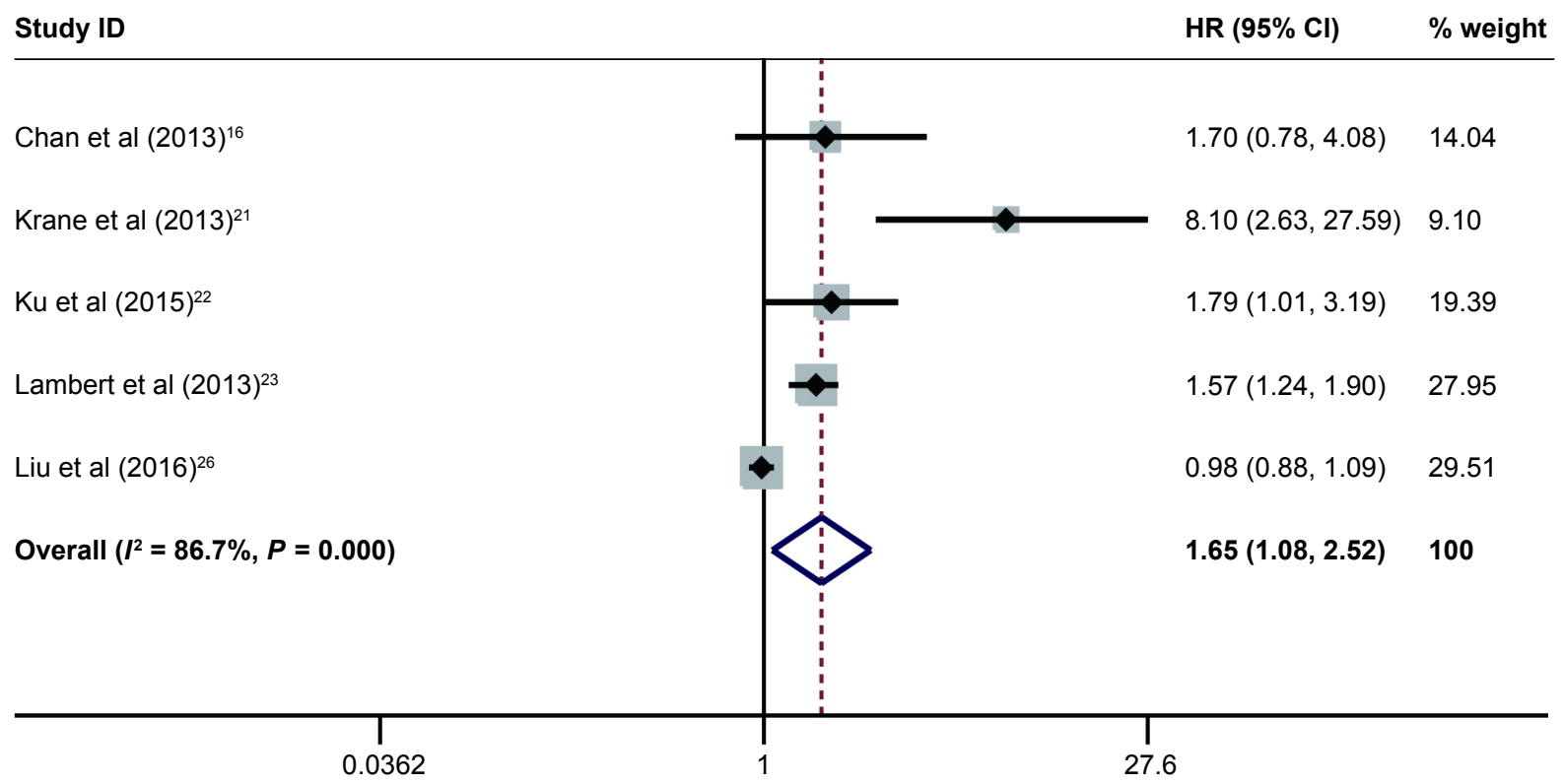

Figure 3 The prognostic significance of low pretreatment serum albumin level on CSS in BC. Note: Weights are from random-effects analysis.

Abbreviations: BC, bladder cancer; CSS, cancer-specific survival; HR, hazard ratio. 


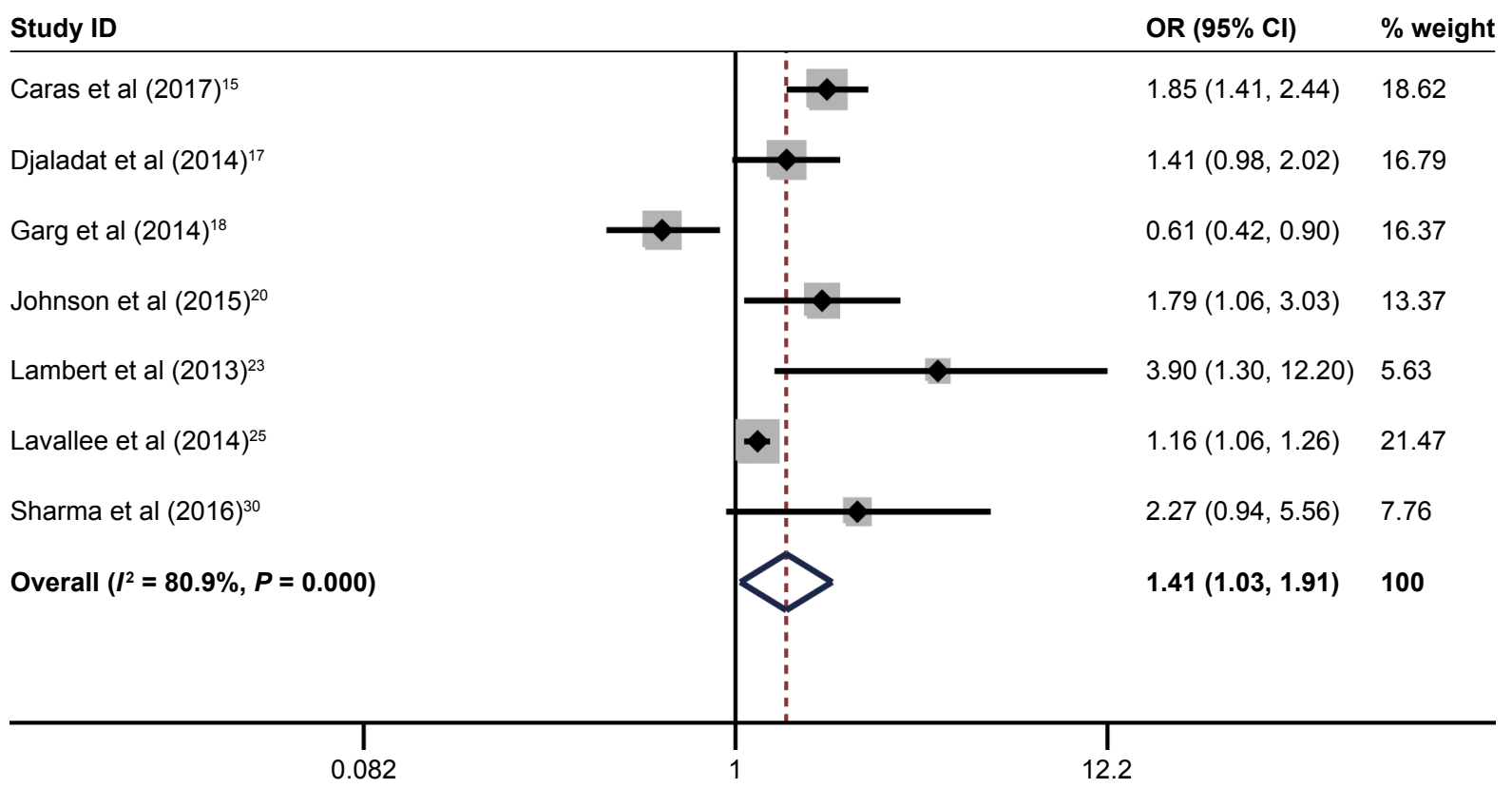

Figure 4 The impact of pretreatment serum albumin on postoperative $30 \mathrm{dC}$.

Note: Weights are from random-effects analysis.

Abbreviations: $30 \mathrm{dC}$, 30-day complication; OR, odds ratio.

Although serum albumin is an inexpensive and easily obtainable index for the prognosis in $\mathrm{BC}$ patients, some issues should be noticed when it is applied to clinical practice. Under some conditions, malnutrition might not be reflected by the concentration of serum albumin. For instance, when cancer patients suffered from dehydrated conditions, the serum albumin level will be normal and even increased, even if they have cancer-related malnutrition. ${ }^{38,39}$ Besides, dietary changes and other factors that are not specifically associated with cancers can also influence the concentration of serum albumin. Therefore, if the interference of these factors is excluded, pretreatment serum albumin would be a reliable

\begin{tabular}{|c|c|c|}
\hline Study ID & OR $(95 \% \mathrm{Cl})$ & $\%$ weight \\
\hline Caras et al $(2017)^{15}$ & $1.71(0.85,3.45)$ & 21.52 \\
\hline Djaladat et al $(2014)^{17}$ & $2.42(1.31,4.45)$ & 28.25 \\
\hline Garg et al $(2014)^{18}$ & $3.03(1.33,7.14)$ & 14.95 \\
\hline Lambert et al $(2013)^{23}$ & $22.96(2.47,213.36)$ & 2.12 \\
\hline Morgan et al $(2011)^{27}$ & $2.50(1.40,4.45)$ & 31.58 \\
\hline Mursi et al $(2013)^{28}$ & $9.20(0.69,122.38)$ & 1.58 \\
\hline Overall $\left(I^{2}=18.2 \%, P=0.295\right)$ & $2.51(1.82,3.48)$ & 100 \\
\hline
\end{tabular}

Figure 5 The impact of pretreatment serum albumin on postoperative $90 \mathrm{dM}$.

Abbreviations: 90dM, 90-day mortality; OR, odds ratio. 
Meta-analysis estimates, given named study is omitted

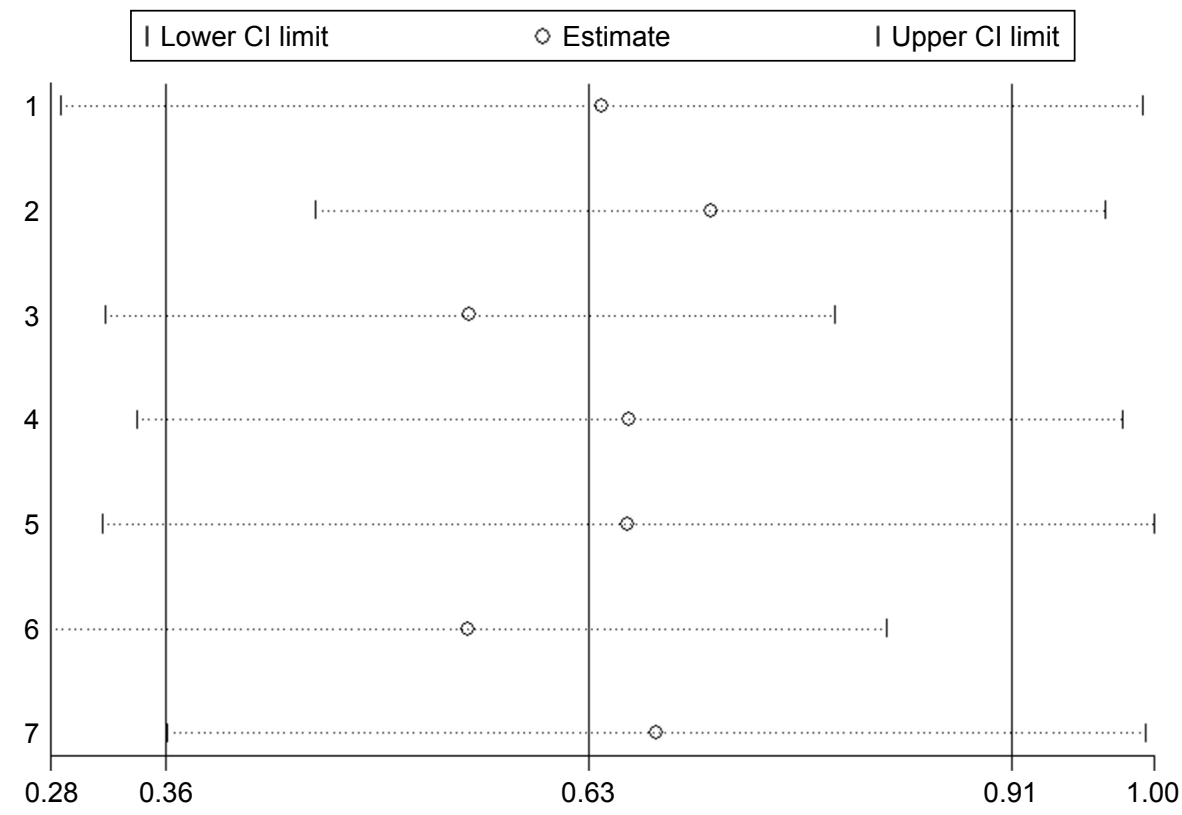

Figure 6 The results of sensitivity analysis of the pooled HR for OS. Abbreviations: HR, hazard ratio; OS, overall survival.

prognostic predictor in $\mathrm{BC}$ patients. For instance, considering those limitations in the clinical practice, recently, to improve the accuracy of risk stratification for cancer patients, many studies have investigated the prognostic values of the combination of serum albumin and other serum markers in cancer patients. For instance, one study suggested that the albumin/ globulin ratio combining the preoperative serum albumin and globulin levels can effectively stratify $\mathrm{BC}$ patients by the prognostic risks. ${ }^{26}$

The results from our meta-analysis might be challenged by several limitations. First, the majority of the included studies were retrospective, which might cause bias in patient

Meta-analysis estimates, given named study is omitted

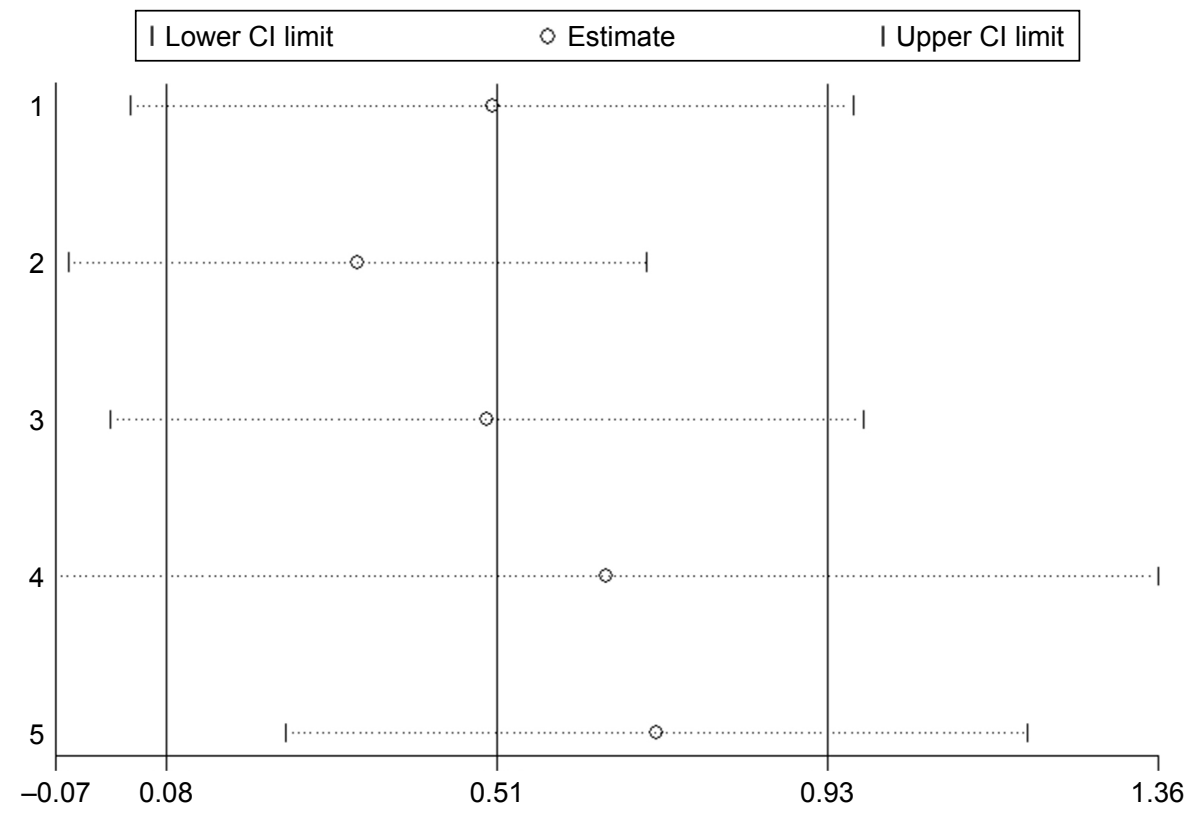

Figure 7 The results of sensitivity analysis of the pooled HR for CSS. Abbreviations: CSS, cancer-specific survival; HR, hazard ratio. 
Meta-analysis estimates, given named study is omitted

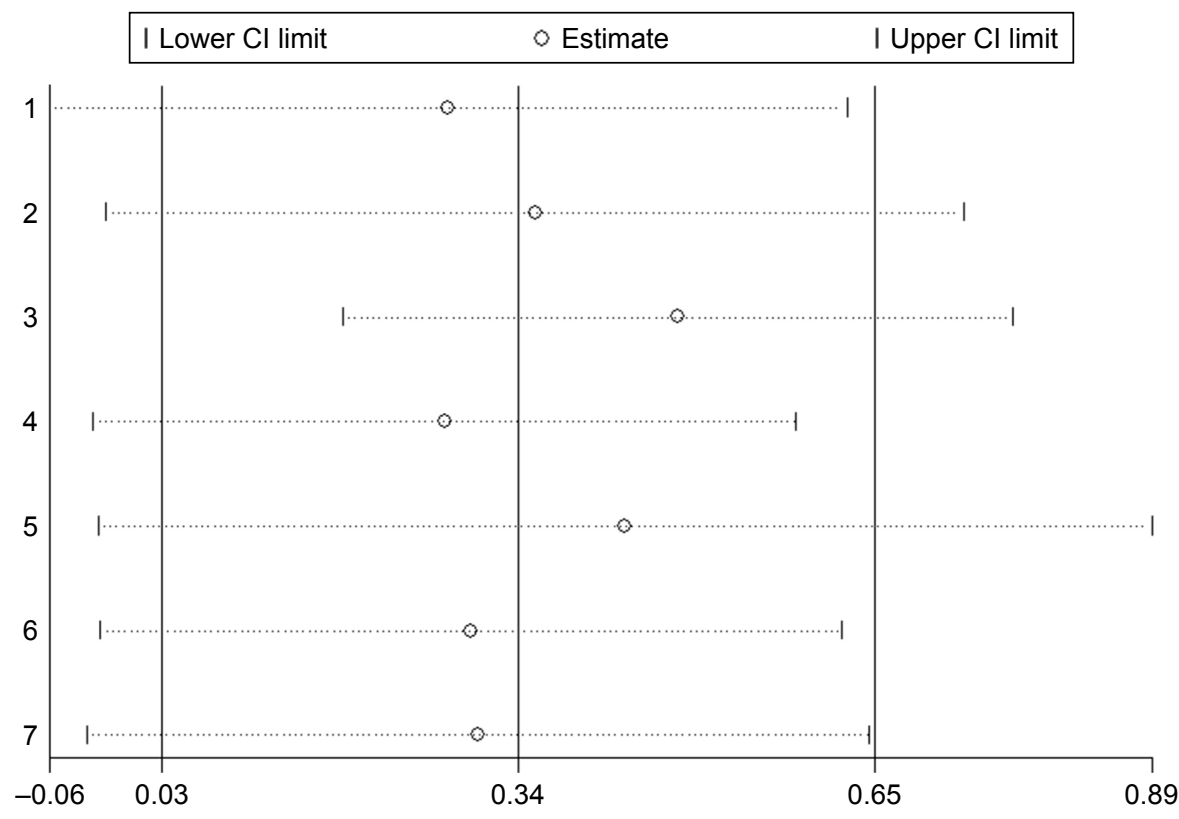

Figure 8 The results of sensitivity analysis of the pooled OR for postoperative $30 \mathrm{dC}$. Abbreviations: $30 \mathrm{dC}$, 30-day complication; OR, odds ratio.

selection and data analysis. Second, all the included studies were published in English, which might lead to some language bias. Third, the cutoffs of high pretreatment serum albumin levels were not in consistency among the included studies. The value of $3.5 \mathrm{~g} / \mathrm{dL}$ was defined as the cutoff value for evaluating serum albumin level in most of the included studies. However, it might be doubtful that $3.5 \mathrm{~g} / \mathrm{dL}$ could act as an accurate cutoff value for evaluating the serum albumin level in $\mathrm{BC}$ patients, considering that the cutoff values for high serum albumin level were $>3.5 \mathrm{~g} / \mathrm{dL}$ in a few studies. Therefore, further high-quality clinical studies with large sample size are needed to determine a definite and efficient

Meta-analysis estimates, given named study is omitted

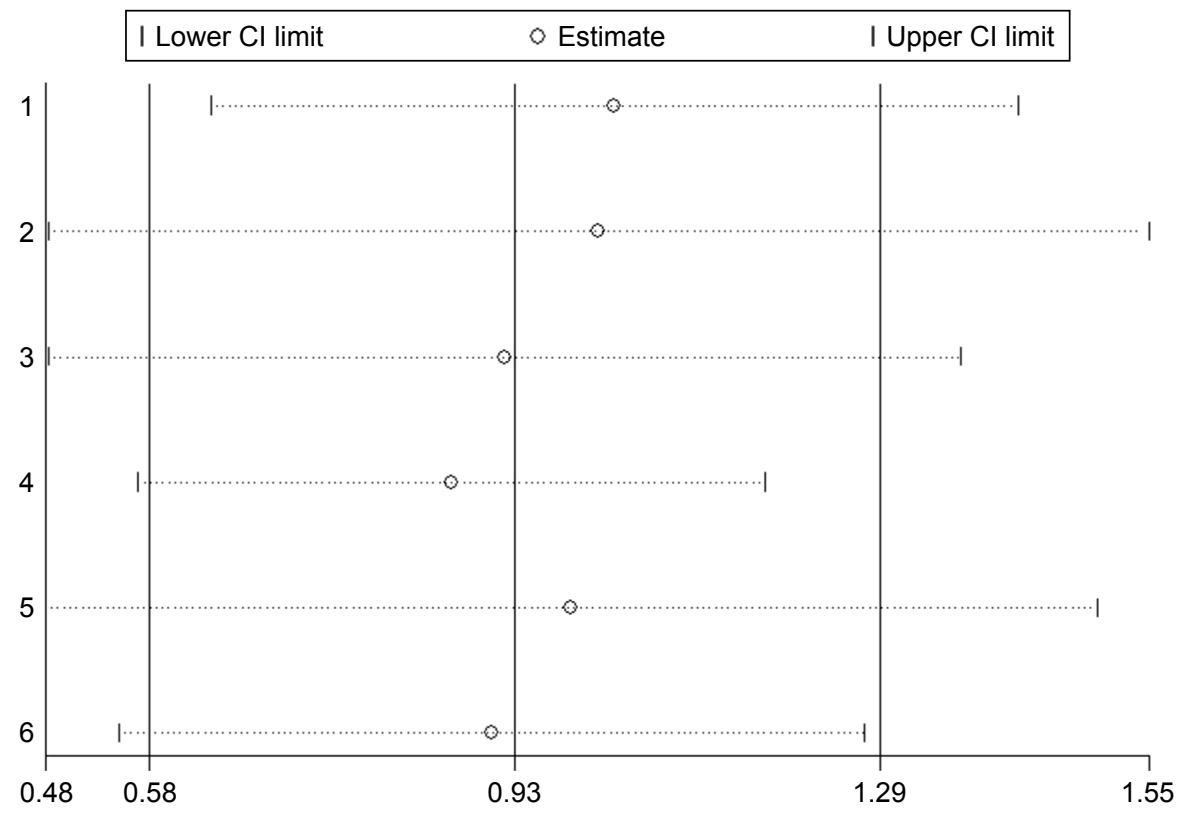

Figure 9 The results of sensitivity analysis of the pooled OR for postoperative $90 \mathrm{dM}$. Abbreviations: 90dM, 90-day mortality; OR, odds ratio. 
Table 3 Subgroup analysis of preoperative serum albumin and outcomes of BC patients

\begin{tabular}{|c|c|c|c|c|c|c|c|c|}
\hline \multirow[t]{2}{*}{ Variables } & \multirow[t]{2}{*}{ Outcome } & \multirow[t]{2}{*}{ Studies } & \multirow[t]{2}{*}{ Patients } & \multirow[t]{2}{*}{ HR (95\% Cl) } & \multirow[t]{2}{*}{$P$-value } & \multirow[t]{2}{*}{ Model } & \multirow{2}{*}{$\begin{array}{l}\text { Heterogeneity } I^{2} \\
\%\end{array}$} & \multirow{2}{*}{$\frac{\text { Erogeneity }}{P \text {-value }}$} \\
\hline & & & & & & & & \\
\hline \multicolumn{9}{|l|}{ Ethnicity } \\
\hline \multirow[t]{2}{*}{ Asian } & OS & 4 & I,655 & $1.37(1.11-1.69)$ & $<0.01$ & Fixed & 0.0 & 0.61 \\
\hline & CSS & 3 & 831 & $1.32(0.8 I-2.14)$ & 0.27 & Random & 65.2 & 0.06 \\
\hline \multirow[t]{2}{*}{ Non-Asian } & OS & 4 & 1,919 & $2.35(1.65-3.34)$ & $<0.01$ & Random & 58.4 & 0.06 \\
\hline & CSS & 2 & 255 & $3.21(0.65-15.80)$ & 0.15 & Random & 86.2 & $<0.01$ \\
\hline \multicolumn{9}{|c|}{ Analysis type } \\
\hline \multirow[t]{3}{*}{ Univariate } & CSS & 1 & 117 & $1.79(0.73-4.37)$ & 0.20 & - & - & - \\
\hline & $90 \mathrm{dM}$ & 5 & 7,426 & $2.42(1.75-3.33)$ & $<0.01$ & Fixed & 31.5 & 0.21 \\
\hline & CSS & 5 & 969 & $1.65(1.03-2.63)$ & 0.04 & Random & 89.7 & $<0.01$ \\
\hline Multivariate & $90 \mathrm{dM}$ & I & I,097 & $3.03(1.31-7.02)$ & 0.01 & - & - & - \\
\hline \multicolumn{9}{|c|}{ Cutoff value } \\
\hline \multirow[t]{3}{*}{$3.5 \mathrm{~g} / \mathrm{dL}$} & CSS & 2 & 412 & $1.12(0.69-1.82)$ & 0.66 & Fixed & 42.1 & 0.19 \\
\hline & $30 \mathrm{dC}$ & 4 & 7,915 & $1.74(1.39-2.17)$ & $<0.01$ & Fixed & 13.4 & 0.33 \\
\hline & $90 \mathrm{dM}$ & 4 & 7,257 & $2.39(1.54-3.73)$ & $<0.01$ & Fixed & $<0.01$ & 0.12 \\
\hline \multirow[t]{3}{*}{ Others } & CSS & 3 & 674 & $2.22(1.18-4.17)$ & 0.01 & Random & 72.7 & 0.03 \\
\hline & $30 \mathrm{dC}$ & 3 & 3,674 & $1.06(0.61-1.83)$ & 0.85 & Random & 84.3 & $<0.01$ \\
\hline & $90 \mathrm{dM}$ & 2 & 1,266 & $2.66(1.65-4.28)$ & $<0.01$ & Fixed & 0.0 & 0.71 \\
\hline
\end{tabular}

Abbreviations: BC, bladder cancer; CSS, cancer-specific survival; 30dC, 30-day complication; 90dM, 90-day mortality; HR, hazard ratio; OS, overall survival.

cutoff value for judging the serum albumin level in $\mathrm{BC}$ patients before the findings of our study are widely applied to clinical practice. Fourth, the inconsistencies in the follow-up period and the baseline characteristics of patients also existed in this meta-analysis, and they may result in significant heterogeneities, consequently affecting the robustness of the combined analyses. Therefore, we wish to stress that the results of this meta-analysis should be cautiously interpreted, and further large-scale prospective clinical trials are urgently needed to confirm the impact of pretreatment serum albumin level on the outcomes of $\mathrm{BC}$ patients in the future.

\section{Conclusion}

This meta-analysis indicated that decreased pretreatment serum albumin level was correlated with worse survival and higher incidence of postoperative complication and mortality in patients with BC. Nevertheless, further high-quality trials with large sample size should be performed to confirm the results of this meta-analysis.

\section{Disclosure}

The authors report no conflicts of interest in this work.

\section{References}

1. Siegel RL, Miller KD, Jemal A. Cancer statistics, 2016. CA Cancer J Clin. 2016;66(1):7-30.

2. Sanguedolce F, Bufo P, Carrieri G, Cormio L. Predictive markers in bladder cancer: do we have molecular markers ready for clinical use? Crit Rev Clin Lab Sci. 2014;51(5):291-304.

3. Kamat AM, Hahn NM, Efstathiou JA, et al. Bladder cancer. Lancet. 2016; 388(10061):2796-2810.
4. Chou R, Selph SS, Buckley DI, et al. Treatment of muscle-invasive bladder cancer: a systematic review. Cancer. 2016;122(6):842-851.

5. Tian Y, Ma Z, Chen Z, et al. Clinicopathological and prognostic value of Ki-67 expression in bladder cancer: a systematic review and metaanalysis. PLoS One. 2016;11(7): 0158891.

6. Seo SH, Kim SE, Kang YK, et al. Association of nutritional statusrelated indices and chemotherapy-induced adverse events in gastric cancer patients. BMC Cancer. 2016;16(1):900.

7. Levitt DG, Levitt MD. Human serum albumin homeostasis: a new look at the roles of synthesis, catabolism, renal and gastrointestinal excretion, and the clinical value of serum albumin measurements. Int J Gen Med. 2016;9:229-255.

8. Truong A, Hanna MH, Moghadamyeghaneh Z, Stamos MJ. Implications of preoperative hypoalbuminemia in colorectal surgery. World $J$ Gastrointest Surg. 2016;8(5):353-362.

9. Chen X, Long X, Liang Z, et al. Higher N stage and serum ferritin, but lower serum albumin levels are associated with distant metastasis and poor survival in patients with nasopharyngeal carcinoma following intensity-modulated radiotherapy. Oncotarget. 2017;8(42):73177-73186.

10. Bosaeus I. Nutritional support in multimodal therapy for cancer cachexia. Support Care Cancer. 2008;16(5):447-451.

11. Ataseven B, du Bois A, Reinthaller A, et al. Pre-operative serum albumin is associated with post-operative complication rate and overall survival in patients with epithelial ovarian cancer undergoing cytoreductive surgery. Gynecol Oncol. 2015;138(3):560-565.

12. Chiang JM, Chang CJ, Jiang SF, et al. Pre-operative serum albumin level substantially predicts post-operative morbidity and mortality among patients with colorectal cancer who undergo elective colectomy. Eur J Cancer Care (Engl). 2017;26(2).

13. Jiang Z, Li Y, Han G, et al. 术前血清白蛋白水平与结肠癌临床病 理特征及生存预后的关系 [Association of serum albumin level with clinicopathologic features and prognosis in colon cancer]. Zhonghua Wei Chang Wai Ke Za Zhi. 2016;19(1):80-83.

14. Chen Z, Shao Y, Wang K, et al. Prognostic role of pretreatment serum albumin in renal cell carcinoma: a systematic review and meta-analysis. Onco Targets Ther. 2016;9:6701-6710.

15. Caras RJ, Lustik MB, Kern SQ, McMann LP, Sterbis JR. Preoperative albumin is predictive of early postoperative morbidity and mortality in common urologic oncologic surgeries. Clin Genitourin Cancer. 2017; 15(2):e255-e262. 
16. Chan ES, Yip SK, Hou SM, Cheung HY, Lee WM, Ng CF. Age, tumour stage, and preoperative serum albumin level are independent predictors of mortality after radical cystectomy for treatment of bladder cancer in Hong Kong Chinese. Hong Kong Med J. 2013;19(5): 400-406.

17. Djaladat H, Bruins HM, Miranda G, Cai J, Skinner EC, Daneshmand S. The association of preoperative serum albumin level and American Society of Anesthesiologists (ASA) score on early complications and survival of patients undergoing radical cystectomy for urothelial bladder cancer. BJU Int. 2014;113(6):887-893.

18. Garg T, Chen LY, Kim PH, Zhao PT, Herr HW, Donat SM. Preoperative serum albumin is associated with mortality and complications after radical cystectomy. BJU Int. 2014;113(6):918-923.

19. Hinata N, Miyake H, Miyazaki A, Nishikawa M, Tei H, Fujisawa M. Performance status as a significant prognostic predictor in patients with urothelial carcinoma of the bladder who underwent radical cystectomy. Int J Urol. 2015;22(8):742-746.

20. Johnson DC, Riggs SB, Nielsen ME, et al. Nutritional predictors of complications following radical cystectomy. World J Urol. 2015;33(8): 1129-1137.

21. Krane LS, Richards KA, Kader AK, Davis R, Balaji KC, Hemal AK. Preoperative neutrophil/lymphocyte ratio predicts overall survival and extravesical disease in patients undergoing radical cystectomy. J Endourol. 2013;27(8):1046-1050.

22. Ku JH, Kang M, Kim HS, Jeong CW, Kwak C, Kim HH. The prognostic value of pretreatment of systemic inflammatory responses in patients with urothelial carcinoma undergoing radical cystectomy. Br J Cancer. 2015;112(3):461-467.

23. Lambert JW, Ingham M, Gibbs BB, Given RW, Lance RS, Riggs SB. Using preoperative albumin levels as a surrogate marker for outcomes after radical cystectomy for bladder cancer. Urology. 2013;81(3): 587-592.

24. Laurent M, Brureau L, Demery ME, et al. Early chemotherapy discontinuation and mortality in older patients with metastatic bladder cancer: the AGEVIM multicenter cohort study. Urol Oncol. 2017;35(1): 34.e9-34.e16.

25. Lavallee LT, Schramm D, Witiuk K, et al. Peri-operative morbidity associated with radical cystectomy in a multicenter database of community and academic hospitals. PLoS One. 2014;9(10):e111281.

26. Liu J, Dai Y, Zhou F, et al. The prognostic role of preoperative serum albumin/globulin ratio in patients with bladder urothelial carcinoma undergoing radical cystectomy. Urol Oncol. 2016;34(11): 484.e481-484.e488.
27. Morgan TM, Keegan KA, Barocas DA, et al. Predicting the probability of 90-day survival of elderly patients with bladder cancer treated with radical cystectomy. J Urol. 2011;186(3):829-834.

28. Mursi K, ElFayoumy H, Saad I, Tawakol A, Badawy H. The effect of preoperative clinical variables on the 30- and 90-day morbidity and mortality after radical cystectomy: a single-centre study. Arab J Urol. 2013; 11(2):152-158.

29. Nakagawa T, Taguchi S, Uemura Y, et al. Nomogram for predicting survival of postcystectomy recurrent urothelial carcinoma of the bladder. Urol Oncol. 2017;35(7):457.e415-457.e421.

30. Sharma P, Henriksen CH, Zargar-Shoshtari K, et al. Preoperative patient reported mental health is associated with high grade complications after radical cystectomy. $J$ Urol. 2016;195(1):47-52.

31. Taguchi S, Nakagawa T, Uemura Y, et al. Validation of major prognostic models for metastatic urothelial carcinoma using a multi-institutional cohort of the real world. World J Urol. 2016;34(2):163-171.

32. Tierney JF, Stewart LA, Ghersi D, Burdett S, Sydes MR. Practical methods for incorporating summary time-to-event data into meta-analysis. Trials. 2007;8:16.

33. Stang A. Critical evaluation of the Newcastle-Ottawa scale for the assessment of the quality of nonrandomized studies in meta-analyses. Eur J Epidemiol. 2010;25(9):603-605.

34. Lau J, Ioannidis JP, Schmid CH. Quantitative synthesis in systematic reviews. Ann Intern Med. 1997;127(9):820-826.

35. McMillan DC, Watson WS, O'Gorman P, Preston T, Scott HR, McArdle CS. Albumin concentrations are primarily determined by the body cell mass and the systemic inflammatory response in cancer patients with weight loss. Nutr Cancer. 2001;39(2):210-213.

36. Chojkier M. Inhibition of albumin synthesis in chronic diseases: molecular mechanisms. J Clin Gastroenterol. 2005;39(4 suppl 2):S143-S146.

37. Gupta D, Lis CG. Pretreatment serum albumin as a predictor of cancer survival: a systematic review of the epidemiological literature. Nutr J. 2010;9:69.

38. Detsky AS, Baker JP, Mendelson RA, Wolman SL, Wesson DE, Jeejeebhoy KN. Evaluating the accuracy of nutritional assessment techniques applied to hospitalized patients: methodology and comparisons. JPEN J Parenter Enteral Nutr. 1984;8(2):153-159.

39. Mahdavi AM, Ostadrahimi A, Safaiyan A. Subjective global assessment of nutritional status in children. Matern Child Nutr. 2010;6(4) 374-381.
OncoTargets and Therapy

\section{Publish your work in this journal}

OncoTargets and Therapy is an international, peer-reviewed, open access journal focusing on the pathological basis of all cancers, potential targets for therapy and treatment protocols employed to improve the management of cancer patients. The journal also focuses on the impact of management programs and new therapeutic agents and protocols on

\section{Dovepress}

patient perspectives such as quality of life, adherence and satisfaction. The manuscript management system is completely online and includes a very quick and fair peer-review system, which is all easy to use. Visit http://www.dovepress.com/testimonials.php to read real quotes from published authors. 